\title{
Perencanaan Pengangkatan Buatan dengan Sistim Pemompaan Berdasarkan Data Karakteristik Reservoir
}

\author{
Artificial Lift Design with Pump System Based On reservoir Characteristics \\ Fitrianti \\ Jurusan Teknik Perminyakan Fakultas Teknik Universitas Islam Riau \\ Jl. Kaharuddin Nasution 113 Pekanbaru-28284 \\ Fitrianti94@yahoo.com
}

\begin{abstract}
Abstrak
Pemilihan metode artificial lift terutama dengan menggunakan sitem pemompaan yang sesuai dapat memberikan hasil optimum adalah sangat penting untuk dilakukan, karena menyangkut keekonomian dari sumur produksi suatu lapangan. Selain itu juga diperlukan evaluasi dan perencanaan ulang karena perubahan kondisi reservoir selama masa produksi.
\end{abstract}

Kata-kata kunci: Artificial lift

\begin{abstract}
Choosing the artificial lift method that can give optimal result is important, because it has relationship whit economical condition of production well in a oil field. Beside that, evaluation and redesign of artificial lift method are important because of reservoir conditions as long as production time.
\end{abstract}

Keywords: Artificial lift

\section{PENDAHULUAN}

Penyelesaian sumur-sumur pengangkatan buatan memerlukan studi lebih lanjut dan mendalam. Dengan mengetahui metode pengangkatan buatan yang paling tepat dan sesuai, diharapkan hasil yang diperoleh semaksimal mungkin tanpa menyebabkan tingginya biaya produksi. Penentuan metode pengangkatan buatan dipengaruhi beberapa faktor antara lain: lokasi lapangan (onshoreatau offshore), ketersediaan sumber tenaga (listrik dan gas), kondisi reservoir (GOR, produktifitas sumur, water cut, tekanan alir dasar sumur), kondisi fluida (viskositas dan kandungan pasir), kondisi lubang sumur (temperatur, kedalaman dan kemiringan), faktor ekonomi, produksi sumur, kelebihan dan kekurangan yang dimiliki masing-masing metode

\section{TEORI DASAR}

\section{Sucker Rod Pump (SRP)}

Pompa angguk atau sucker rod pump merupakan salah satu teknik pengangkatan buatan atau artificial lift yang digunakan untuk membantu mengangkat minyak dari lubang sumur ke permukaan sebagai akibat dari penurunan energi alami yang dimilikireservoir, dimana untuk mengangkat minyak dari dalam 
sumur ke permukaan digunakan pompa dengan rod (tangkai pompa).

\section{Prinsip Kerja Pompa Angguk}

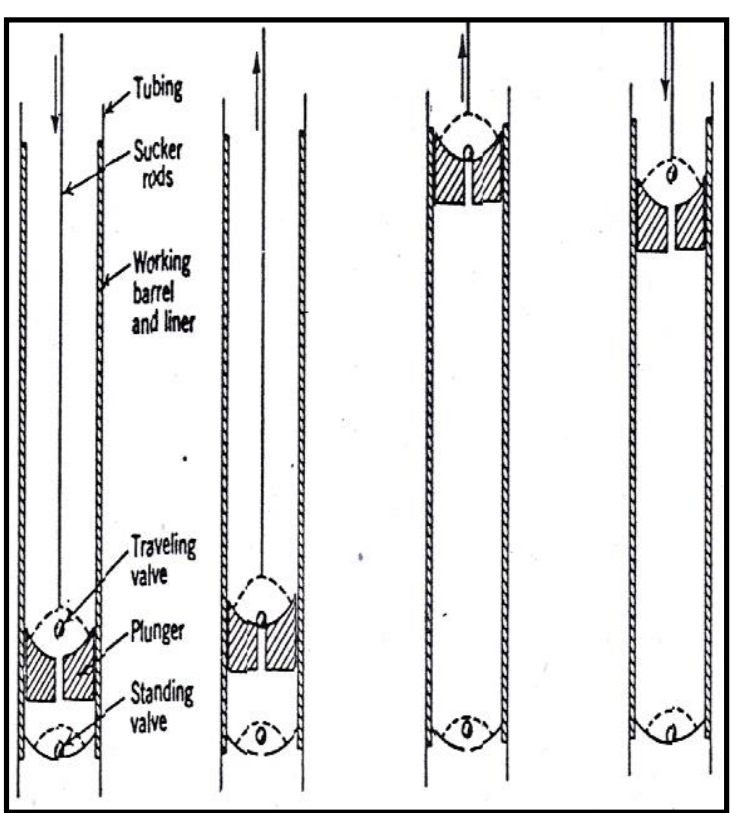

Gambar 1. Mekanisme Kerja Pompa

Angguk (K.E. Brown, 1980)

\section{Keterangan :}

a. Plunger bergerak ke bawah, dekat dasar langkah pemompaan

Fluida bergerak ke atas melalui traveling valve yang terbuka, sedangkan berat kolom fluida di tubing ditahan oleh standing valve yang tertutup. Apabila tekanan aliran dasar sumur lebih besar daripada berat kolom fluidanya maka standing valve akan terbuka walaupun plunger berada dekat dasar langkah pemompaannya dan sumur dapat mengalirkan fluida.

b. Plunger bergerak ke atas, dekat dasar langkah pemompaan
Traveling valve tertutup, sehingga berat kolom fluida akan dipindahkan dari tubing ke rod string. Standing valve akan terbuka segera setelah tekanan dasar sumur lebih besar dari pada tekanan yang terdapat antara standing valve dan traveling valve. Jadi hal ini tergantung pump spacing yaitu volume yang ada pada standing valve dan traveling valve pada dasar stroke dan persentase gas bebas yang terjebak di ruang ini.

c. Plunger bergerak ke atas, dekat puncak langkah pemompaan. Jika ada produksi karena pemompaan maka standing valve akan terbuka sehingga fluida formasi dapat masuk ke tubing. Pada saat ini traveling valve tertutup.

d. Plunger bergerak ke bawah, dekat puncak langkah pemompaan.

Karena tekanan yang diakibatkan oleh kompresi fluida yang ada dalam ruang antara standing valve dan traveling valve, maka standing valve tertutup, sedangkan traveling valve terbuka. Pada gerak turun tersebut terbukanya traveling valve tergantung dari prosentase gas yang berada di fluida yang terjebak, sebab tekanan di bawah valve harus lebih besar dari yang di atasnya

Setelah plunger mencapai dasar stroke maka langkah (a) sampai (d) diulangi lagi. Proses ini berlangsung berulangkali sehingga minyak dapat mengalir kepermukaan. 


\section{Electric Submersible Pump (ESP)}

Electric Submersible Pump (ESP) adalah pompa yang dimasukkan ke dalam lubang sumur yang digunakan untuk memproduksi minyak secara artificial lift (pengangkatan buatan) dan digerakkan oleh motor listrik.

Electric submersible pump dibuat atas dasar prinsip pompa sentrifugal bertingkat banyak dimana keseluruhan dari pompa dan motornya ditenggelamkan kedalam cairan. Electric submersible pump digunakan pada sumursumur yang dalam dan dapat memberikan laju produksi yang besar. Selain untuk sumur produksi, ESP juga dapat untuk proyek-proyek water flooding dan pressure maintenance, dimana ESP dipasang pada sumur-sumur injeksi. Selain dari itu dapat juga digunakan pada sumur-sumur yang tidak menggunakan tubing (tubingless completion) dan produksi dilakukan melalui casing. Pada umumnya pompa jenis ini digunakan pada sumur-sumur artificial lift dengan produksi besar dan GOR rendah.

Pompa ESP biasanya dipakai untuk laju produksi 200-2500 STB/day, walaupun dapat digunakan untuk produksi sampai 95000 STB/day. Pompa ESP umumnya digunakan pada sumur miring di daerah lepas pantai. Didaratan hanya digunakan untuk laju produksi tinggi yaitu diatas 2000STB/day, karena pompa angguk akan lebih ekonomis untuk sumur dengan laju produksi rendah.

\section{Prinsip Kerja Electric Submersible Pump}

Prinsip kerja Electric Submersible Pump adalah berdasarkan pada prinsip kerja pompa sentrifugal dengan sumbu putarnya tegak lurus. Pompa sentrifugal adalah motor hidrolik dengan jalan memutar cairan yang melalui impeller pompa, cairan masuk ke dalam impeller pompa menuju poros pompa, dikumpulkan oleh diffuser kemudian akan dilempar keluar. Oleh impeller, tenaga mekanis motor dirubah menjadi tenaga hidrolik. Impeller terdiri dari dua piringan yang didalamnya terdapat sudu-sudu. Pada saat impeller diputar dengan kecepatan sudut $\omega$, cairan dalam impeller dilemparkan keluar dengan tenaga potensial dan kinetik tertentu. Cairan yang ditampung dalam rumah pompa kemudian dievaluasikan melalui diffuser, sebagian tenaga kinetik dirubah menjadi tenaga potensial berupa tekanan. Karena cairan dilempar ke luar maka terjadi proses penghisapan. 


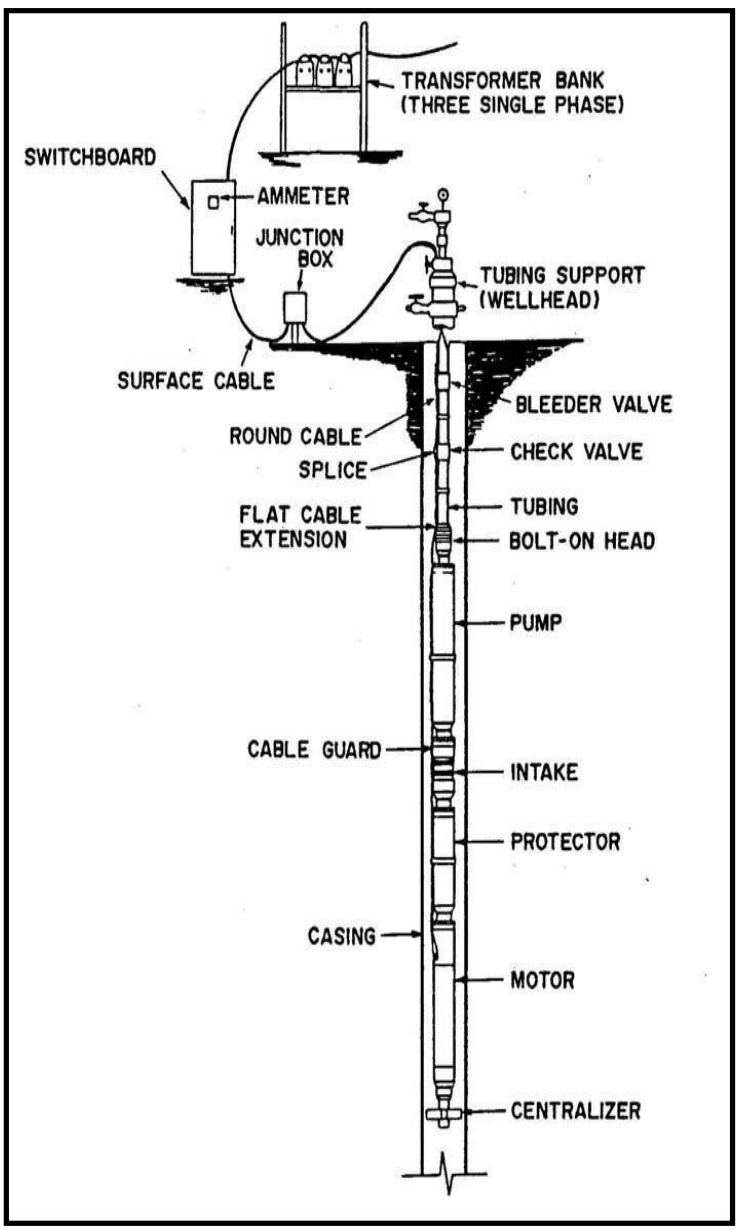

Gambar 2. Instalasi Electric Submersible

Pump (K. E. Brown, 1980)

\section{Progressive Cavity Pump (PCP)}

Progressive Cavity Pump (PCP) merupakan salah satu jenis pompa putar (rotary pump) yang terdiri dari rotor berbentuk ulir yang digerakkan oleh penggerak melalui rod dan drive head, serta berputar didalam stator yang merupakan bagian diam dari pompa yang dihubungkan kepermukaan oleh tubing.

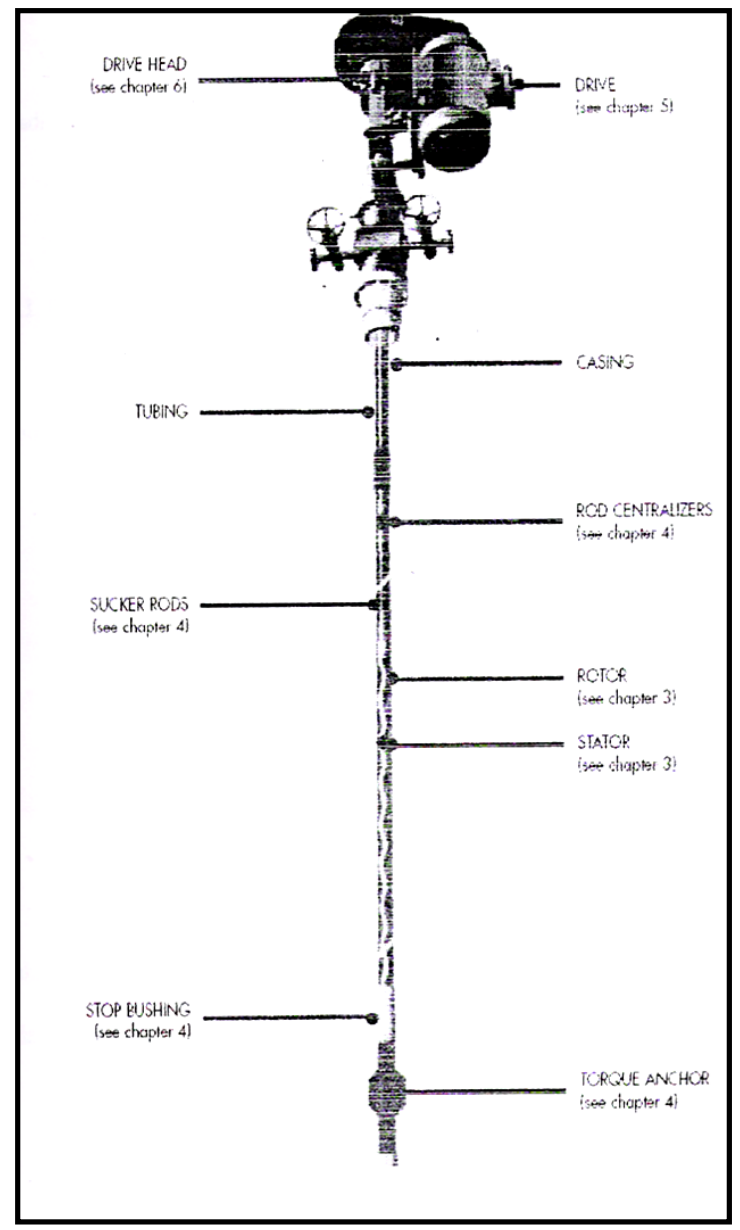

Gambar 3. Progressing Cavity Pump (S.

Sudrajat, 2003)

Prinsip Kerja Progressive Cavity Pump (PCP) Pada PCP prinsip yang bekerja yaitu proses pemindahan rongga-rongga yang terbentuk antara rotor dan stator yang berlangsung secara terus-menerus dimana motor yang berputar dalam stator. Pada waktu rotor berputar secara eksentris daidalam stator serangkaian ronggarongga (cavities) yang terpisah $180^{\circ}$ satu sama lain bergerak maju dari sisi sebelah bawah naik menuju sisi pompa sebelah atas. Pada saat rongga yang satu mengecil, rongga yang 
bersebelahan akan membesar dengan kecepatan yang sama sehingga terjadi aliran fluida tanpa kejutan-kejutan, karena tidak ada katup (valve) seperti pada pompa sucker rod sehingga tidak ada gas yang terperangkap (gas lock) yang dapat mengurangi efisiensi pompa dan aliran yang ada berlangsung secara kontinyu dengan kecepatan rendah yang konstan (low velocity non-pulsating positive displacement). Pompa jenis ini mampu menahan telanan tersekat masing-masing rongg satu sama lain oleh suatu seal yang terbentuk seperti garis (seal line) antara rotor dan stator atau tepatnya pada bagian elastomernya.

\section{Hydraulic Pumping Unit (HPU)}

Hydraulic Pump merupakan salah satu metode artificial lift dimana system pengangkatan cairan dengan pompa hidrolik memanfaatkan cairan bertekanan tinggi (power fluid) sebagai sumber tenaga untuk menggerakkan pompa di bawah permukaan. Pada umumnya pompa HPU digunakan pada sumur yang dalam. Pemasangan HPU ditujukan pada sumursumur pompa yang mempunyai aliran yang rendah dengan ciri-ciri reservoir permeabilitas dan tekanan rendah, tetapi memiliki oil cut yang masih tinggi. HPU memiliki keunggulan dibandingkan jenis pengangkatan buatan lainnya, karena kapasitas terangkatnya fluida bisa disesuaikan kapan saja sesuai dengan kondisi reservoir. Keunggulan lainnya adalah mudah dalam pemasangan, pemeliharaan, serta bisa dipindah-pindah dari satu sumur ke sumur lainnya tanpa harus membongkar unit permukaannya.

\section{Prinsip Kerja HPU}

HPU merupakan alat yang terdiri dari unit permukaan dan unit bawah permukaan. Unit permukaan berbentuk silinder dengan sistim torak, dipasang di atas permukaan. Unit bawah permukaan prinsip kerjanya sama dengan prinsip kerja pompa angguk, dimana pada waktu upstroke ruangan antara standing valve dan travelling valve akan bertambah besar/panjang dan ini akan mengakibatkan kurangnya tekanan di dalam pompa sehingga fluida masuk melalui standing valve yang terbuka disebabkan tekanan dari fluida diluar pompa dengan isapan plunger. Saat plunger sampai batas ketinggian yang bisa diangkat, maka standing valve dengan sendirinya menutup (plunger duduk kembali pada kedudukannya) sehingga fluida tidak dapat keluar lagi dari pompa. Selanjutnya pada waktu downstroke dari plunger, standing valve tidak bisa terbuka lagi dan oleh tekanan ke bawah fluida tidak dapat lewat antara plunger dengan dinding pompa, maka travelling valve akan terbuka dan fluida akan naik ke dalam tubing. Keadaan yang akan terus berkelanjutan inilah yang membuat fluida terus-menerus bertambah dalam tubing dan naik ke permukaan kemudian ke tangki penyimpanan melalui separator. 


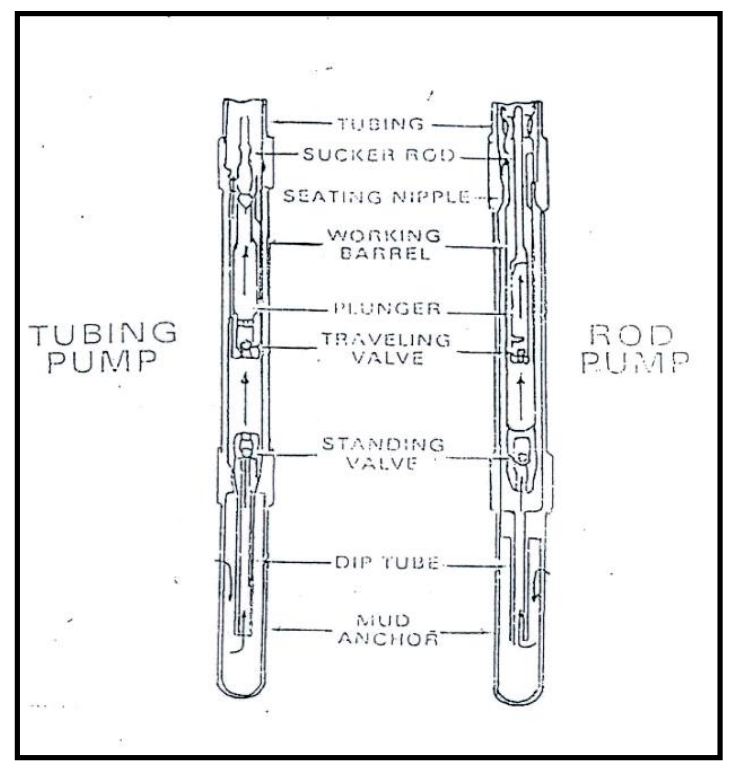

Gambar 4. Perbedaan Tubing Pump dan Rod

Pump (N. Huda, 2003)

\section{Jet Pump (Pompa Jet)}

Pompa jet atau jet pump telah dikembangkan sejak tahun 1930. Jet pump mulai popular pada tahun 1970 di industri minyak dan sangat populer digunakan di perumahan untuk memompa air. Jet pump cukup baik untuk memproduksi minyak dengan laju cukup besar, karena biaya operasi rendah, tidak mudah rusak karena tidak ada bagian metal yang bergerak, toleran terhadap pasir dan sedikit gas (gas tersebut dapat membantu mengangkat minyak ke atas bila GOR 400-500 SCF/STB) mengimbangi kehilangan efisiensi pompanya. Laju produksinya 50-12000 B/D Jet pump merupakan salah satu dari hanya dua kemungkinan artificial lift yang dapat digunakan di subsea offshore, karena pipa salur di dalam laut radius putarannya kecil, sehingga hanya gas lift valve dan jet pump yang bisa lewat.

\section{Prinsip Kerja Jet Pump}

Pompa jet adalah hidrodinamis seperti ESP dan bukannya statis seperti PHP ataupun SRP. Prinsip kerjanya adalah berdasarkan transfer momentum antara dua aliran power fluid bertekanan tinggi yang dialirkan melalui suatu nozel dan energi potensial (tekanan) diubah ke energi kinetis dalam bentuk kecepatan tinggi atau jet. Fluida produksi bercampur dengan power fluid di pipa pencampuran yang disebut throat. Dengan bercampurnya power fluid dengan fluida produksi maka momentum dipindahkan ke fluida produksi sehingga energinya akan meningkat. Dengan dilakukannya pencampuran tersebut (pipa melebar dengan sudut sekitar $6^{\circ}$ ) maka kecepatan fluida (terutama power fluid ) akan berkurang dan sebagian energinya diubah kembali ke energi potensial (tekanan) yang cukup untuk mengirim campuran (power fluid balik dan produksi) tersebut ke permukaan. Ukuran dan bentuk nozle serta throat mempengaruhi laju aliran sedangkan perbandingan luas nozle dan throat mempengaruhi head yang terjadi selain juga laju aliran yang berhubungan dengan head itu seperti juga pada ESP. Makin besar perbandingan nozle terhadap throat maka makin besar pula head yang bisa didapat, karena laju produksi yang didapat berkurang dan berarti bahwa makin besar momentum 
yang bisa diserap oleh produksi tadi. Keadaan ini cocok untuk kedalaman pompa yang relative dalam dengan laju produksi rendah. Apabila perbandingan nozzle terhadap throat berkurang, maka luas daerah masuknya fluida produksi lebih besar tetapi head kecil. Pompa jet ini sesuai untuk sumur dangkal dengan laju produksi relatif besar.

Faktor-faktor tersebut perlu diperhatikan dalam perencanaan pengangkatan buatan menggunakan pompa jet. Selain hal tersebut di atas, faktor lain yang harus diperhatikan pula adalah kavitasi (cavitation), yaitu keadaan dimana kecepatan fluida yang masuk terlalu cepat, sehingga tekanan turun di bawah tekanan titik gelembung (bubble point pressure), sehingga gelembung gas yang keluar dari larutan akan mengakibatkan getaran (shock wave) yang dapat mengikis dinding throat. Kerusakan pompa dapat terjadi dalam waktu relative singkat (beberapa jam atau beberapa hari saja setelah kejadian tersebut).

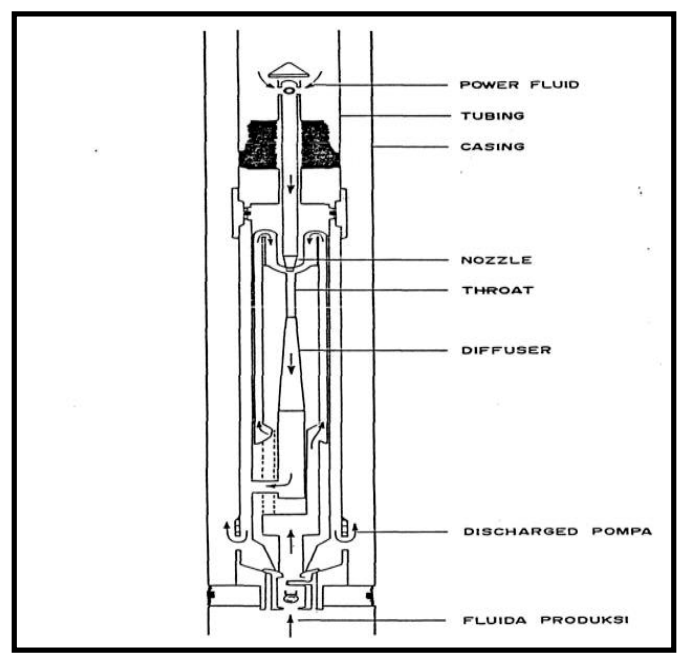

Gambar 5. Pompa Jet (K. E. Brown, 1980)

\section{PEMBAHASAN}

Metode Artificial Lift dapat dibedakan menjadi:gas lift, metode pompa (sucker rod, electric submersible pump, progressive cavity pump, hydraulic pumping unit, dan jet pump). Faktor yang mempengaruhi pemilihan metode yang digunakan dalam metode Artificial Lift adalah: kondisi reservoir (GOR, produktifitas sumur, water cut, Pwf, dan mekanisme pendorong reservoirnya), kondisi fluida (viskositas, densitas, kompresibilitas, kandungan pasir), kondisi lubang sumur (temperatur, kedalaman sumur, kemiringan lubang sumur), penyediaan sumber tenaga, problem produksi, faktor ekonomi, lokasi produksi di darat (onshore) atau lepas pantai (offshore), kelebihan dan kekurangan masingmasing metode artificial lift.

Untuk gas-oil ratio yang berkisar antara 500 scf/STB hingga 2000 scf/STB metode artificial lift yang dapat digunakan adalah continous gas lift, sucker rod pump, electric submersible pump, cavity pump, hydraulic pump piston dan jet pump. Untuk GOR lebih dari 2000 scf/STB, continous gas lift adalah satu-satunya metoda pengangkatan buatan yang direkomendasikan.

Sucker rod pump, electric submersible pump, hydraulic pump piston, cavity pump dan jet pump dapat digunakan sebagai metoda pengangkatan buatan pada sumur dengan laju produksi minyak kurang dari $1000 \mathrm{~B} / \mathrm{D}$, yang dianggap termasuk sumur yang produktivitasnya rendah. 
Continous gas lift, electric submersible pump, progressive cavity pump hydraulic pump piston dan jet pump direkomendasikan sebagai metoda pengangkatan buatan pada sumur dengan laju produksi minyak berada pada selang antara $1000 \mathrm{~B} / \mathrm{D}$ sampai $10000 \mathrm{~B} / \mathrm{D}$.

metoda pengangkatan buatan yang direkomendasikan untuk sumur dengan laju produksi minyak lebih besar dari $10000 \mathrm{~B} / \mathrm{D}$ adalah continous gas lift dan electric submersible pump

Sumur dengan water cut yang tinggi membutuhkan metoda pengangkatan buatan dengan kapasitas pengangkatan cairan yang besar seperti continous gas lift, electric submersible pump, cavity pump, hydraulic pump piston dan jet pump.

Reservoir water drive merupakan reservoir yang mempunyai harga water cut yang tinggi dan adanya water influx sehingga metode produksi yang paling sesuai digunakan adalah pompa (sucker rod, ESP, cavity pump , hydraulic pump piston dan jet pump).

Reservoir gas cap drive merupakan reservoir yang mempunyai fasa gas yang berasal dari gas cap sehingga metode produksi artificial lift yang paling sesuai digunakan adalah gas lift.

Reservoir solution gas drive merupakan reservoir yang mempunyai perbandingan produksi gas-minyak (GOR) yang relatif tinggi sehingga metode produksi artificial lift yang paling sesuai digunakan pada reservoir ini adalah gas lift.
Fluida dengan viskositas kurang dari $100 \mathrm{cp}$ merupakan fluida yang encer dan pada kondisi ini baik continous gas lift, sucker rod pump, electric submersible pump, cavity pump, hydraulic pump piston dan jet pump dapat digunakan sebagai metoda pengangkatan buatan. Continous gas lift dan hydraulic pump piston dapat digunakan pada kondisi viskositas fluida berada pada kisaran $100 \mathrm{cp}-500 \mathrm{cp}$. Pada kondisi viskositas fluida lebih besar dari $500 \mathrm{cp}$, continous gas lift, progressive cavity pump, jet pump dan hydraulic pump piston yang direkomendasikan sebagai metoda pengangkatan buatan. Hydraulic pump piston dapat digunakan pada fluida dengan viskositas mencapai $800 \mathrm{cp}$.

Continous gas lift merupakan satu-satunya metoda pengangkatan buatan yang disarankan pada sumur dengan kandungan pasir yang tinggi.

Temperatur lubang sumur yang terlalu tinggi dapat mengurangi operating life dari beberapa peralatan metoda pengangkatan buatan, sehingga penggunaan metoda tersebut menjadi tidak efektif. Pada kondisi temperatur lubang sumur kurang dari $250{ }^{\circ} \mathrm{F}$, baik continous gas lift, sucker rod pump, electric submersible pump, cavity pump, hydraulic pump piston maupun jet pump dapat digunakan sebagai metoda pengangkatan buatan pada sumur tersebut karena batasan temperatur ini merupakan batasan temperatur yang normal. Untuk temperatur Antara $250^{\circ} \mathrm{F}$ sampai $350^{\circ} \mathrm{F}$, continous gas lift, sucker rod pump, hydraulic 
pump piston dapat digunakan sebagai metoda pengangkatan buatan yang dipilih.

Dengan kemajuan ilmu pengetahuan dan teknologi saat ini, gas lift, hydarulic pump piston, electric submersible pump, progressive cavity pump, sucker rod pump dan jet pump dapat digunakan sebagai metoda pengangkatan buatan pada sumur dengan kedalaman kurang dari 14000 ft. Sucker rod pump dapat digunakan pada sumur dengan kedalaman maksimal $14000 \mathrm{ft}$. Electric submersible pump dapat digunakan pada kedalaman lebih dari $14000 \mathrm{ft}$ asalkan berada pada batasan temperatur yang diizinkan. Sedangkan hydraulic pump piston direkomendasikan pada kedalaman lubang sumur lebih dari $14000 \mathrm{ft}$.

\section{KESIMPULAN}

Perencanaan metode produksi membutuhkan peranan dari data karakteristik reservoir.

1. Metode produksi terdiri dari metode sembur alam dan metode sembur buatan, dimana metode pengangkatan buatan meliputi gas lift dan sistim pemompaan (suker rod pump, electric submersible pump, progressive cavity pump, hydraulic pumping unit dan jet pump).

2. Metode sembur alam digunakan apabila tekanan reservoir masih mampu mengangkat fluida kepermukaan. Namun jika tekanan reservoir sudah tidak mampu mengangkat fluida kepermukaan, maka diperlukan tenaga bantuan dengan menggunakan metode pengangkatan buatan (Artificial Lift)

3. Penentuan metode pengangkatan buatan dipengaruhi beberapa faktor antara lain : kondisi reservoir, kondisi fluida, kondisi lubang sumur, lokasi lapangan, ketersediaan sumber tenaga, faktor ekonomi, prediksi performance sumur, kelebihan dan kekurangan yang dimiliki masing-masing metode.

\section{DAFTAR PUSTAKA}

Ahmed, Tarek H., 1989. Hydrocarbon Phase Behaviour, Gulf Publishing Company, Houston, Texas.

Allen, T. O. and Robert, A. P., 1982. Production Operations, Volume I, Oil \& Gas Consultants International, Inc., Tulsa.

Amyx, J. W., D. M. Bass Jr. dan R. L. Whiting, 1960. Petroleum Reservoir Engineering Physical Properties, Mc Graw-Hill Books Company, New York.

Anas Puji Santoso, Ir. MT.,1998. Teknik Produksi I, Jurusan Teknik Perminyakan UPN Veteran Yogyakarta.

Brown, K. E., 1980. The Technology of Artificial Lift Methods, Penn Well Publishimg Co., Tulsa.

Burcik, E. J., 1979. Properties of Petroleum Reservoir Fluid, Jonh Willey and Sons, Inc, New Jersey, 1979. 
Buzarde, L. E, Jr., 1972. Production

Operations Course I - Well

Completion, Society of Petroleum

Engineers of AIME.

Clark, N. J., 1969. Element of Petroleum Reservoir, American Institute Of Mining, Metalurgical and Petroleum Engineering, Inc., Dallas- Texas.

Craft, B. C. dan M. F. Hawkins., 1959. Applied Petroleum Reservoir Engineering, Prentice Hall Inc., englewood Cliffs, New Jersey.

Dale Beggs, H., 1991. Production Optimization, Oli \& Gas Consultants International Inc., Tulsa.

Mc. Cain, William D. Jr., 1979. The Properties Of Petroleum Fluids, Penn Well Publishing Company, Tulsa, Oklahoma.

Pirson, S.J., 1958. Oil Reservoir Engineering, Mc Graw Hill Book Company, Inc., New York.

Sudradjat S., 2003. Weatherford : Artificial Lift System, PT. Catur Khita Persada, Jakarta. 